\title{
ENHANCEMENT OF GEOPHYSICAL DATA FOR KIMBERLITE EXPLORATION AT IRON MOUNTAIN, WYOMING, USA.
}

\author{
$M_{e m m i}{ }^{(1),(2)}$, J.M. and McCallum ${ }^{(1)}$, M.E.
}

(1) Department of Earth Resources, Colorado State University, Fort Collins, CO 80523 USA; (2) Present address: Department of Geological Sciences, Ohio State University, Columbus, OH 43210 USA.

Composite geophysical data from the Iron Mountain Kimberlite District indicate enhancement of geophysical data may aid in kimberlite exploration by accentuating or revealing subtle anomalies. Surface total magnetic field intensity and conductivity data were processed jointly to assess the utility of their combination for rapid and reliable kimberlite detection. Several anomalies, interpreted to reflect kimberlite, were identified in both geophysical and enhanced data from the Iron Mountain area (Figure 1). Most aberrations generally occur on trend with known kimberlite blows and likely mark the subsurface extension or feeder dikes of these intrusions, or separate bodies emplaced along a common structural trend.

Magnetic and conductivity data were subjected to first through fifth degree complete multinomial regression analysis, with station location and elevation used as predictors. Observations, predictions and residuals from the "best" statistically significant regression equation, chosen on the basis of maximum adjusted $\mathrm{R}^{2}$ difference, were related to $a$ mutual reference 1 ine by ranking and standardization. Subsequently, corresponding components of both the ranked and standardized conductivity and magnetic data were manipulated arithmetically. The best tools for detecting and isolating kimberlite occurrences are magnetic/conductivity ratios.

Data enhancement by combining magnetic and conductivity values is useful where conventional geophysical techniques yield ambiguous and(or) only subtle results. For the Iron Mountain study area, striking composite data deviations commonly correspond to subtle kimberliterelated anomalies in the original data, especially those attributed to kimberlite in the subsurface (compare profiles 1 and 2 with profiles 3 and 4 in Figure 2). Such intrusions generally generate broad wavelength, low amplitude features in total magnetic field intensity and unclear conductivity responses.

Evaluation of conventional and composite geophysical data suggests the subsurface occurrence of a series of east-west trending kimberlite dikes, some of which serve as feeders for both exposed and blind diatremes and(or) blows (Figure 1). Kimberlite emplacement apparently was controlled by abundant east-west faults and joints. 


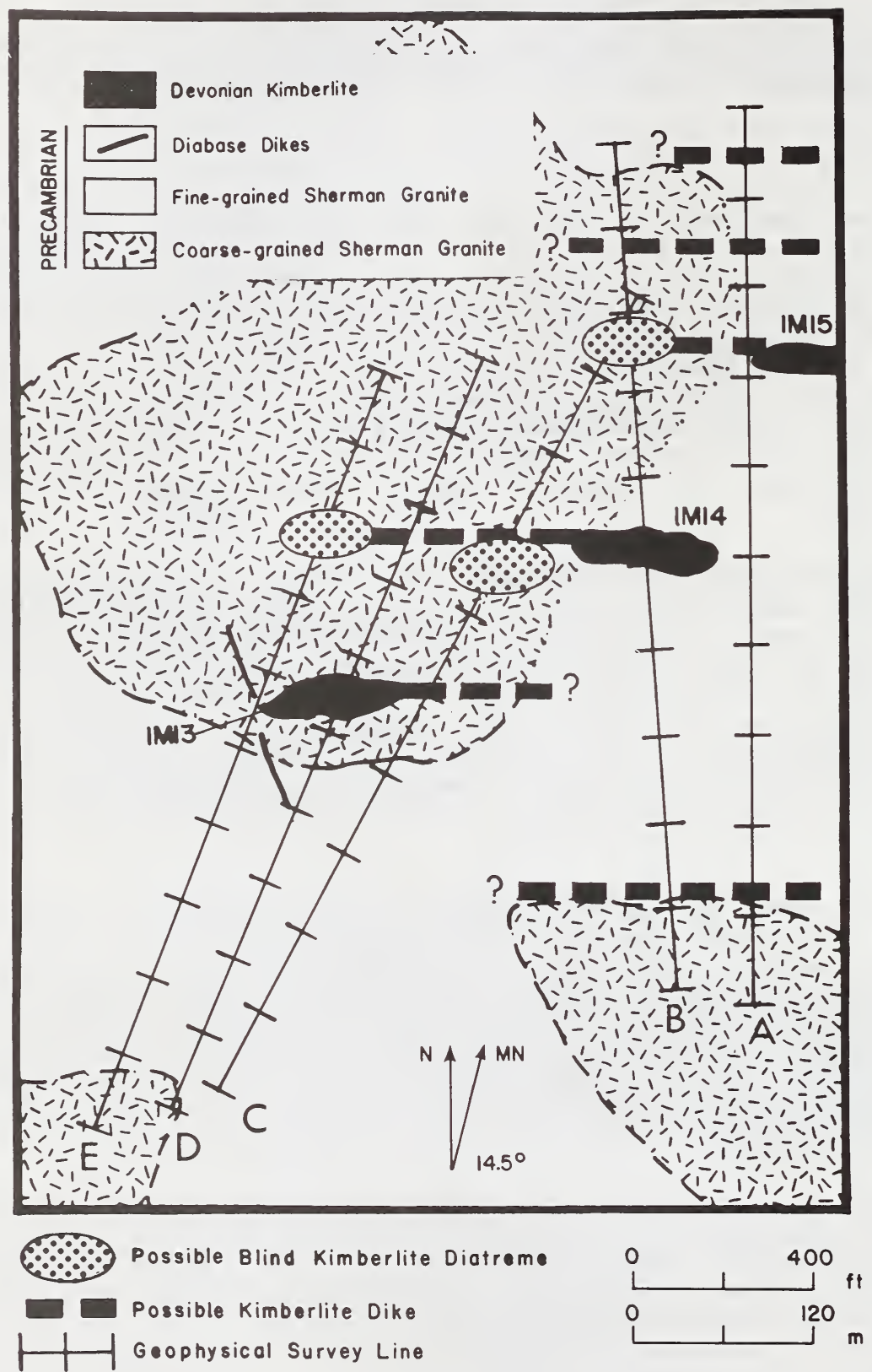

Figure 1. Distribution of hypothesized subsurface kimberlite near kimberlite blows IM13, IM14 and IM15, Iron Mountain Kimberlite District, Wyoming. Suggested subsurface kimberlite occurrerces cie not to scale. 

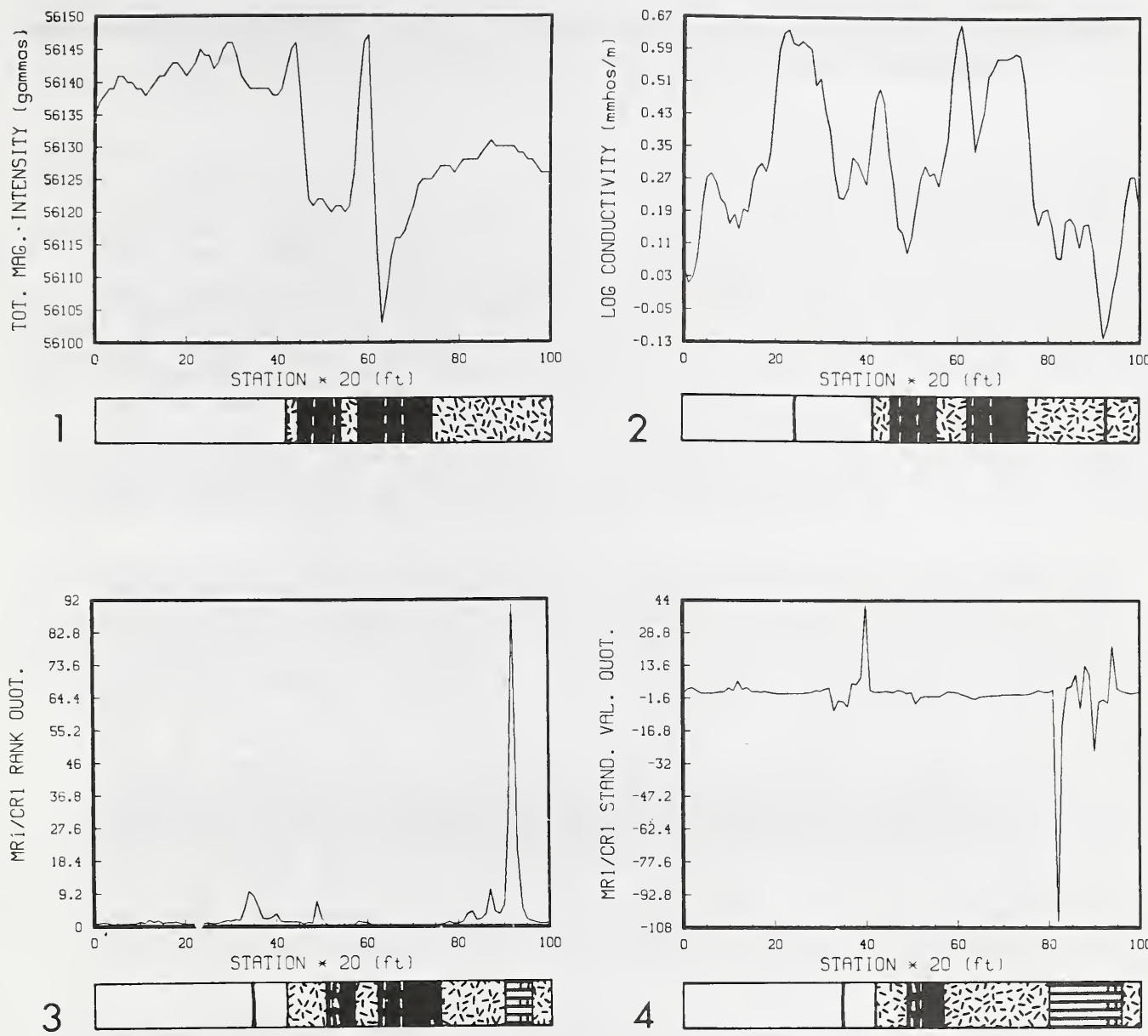

Figure 2. Profiles of conventional and composite geophysical data along Line C, between IM13 and IM14 kimberlite blows, Iron Mountain Kimberlite District, Wyoming (see Figure 1 for location): (1) total magnetic field intensity (2) logarithmic conductivity, (3) residua? rank quotient (MR1 = first degree magnetic residual, $C R 1=$ first degree conductivity residual), (4) residual standardized value quotient. Strip beneath each profile indicates subsurface geology inferred from each set of geophysical data.

Interpretive strip explanation: black = probable kimberlite anomaly, striped pattern = possible kimberlite anomaly, stippled pattern = coarsegrained Sherman Granite, blank = fine-grained Sherman Granite, heavy line = fault or major joint, dashed 1 ine = proposed $\mathrm{kimberlite/granite} \mathrm{contact}$. 